\title{
BMJ Open Quality Improving access to epilepsy care for homeless patients in the Dublin Inner City: a collaborative quality improvement project joining hospital and community care
}

\author{
Elisabeth Doran (10 ,1,2 Enda Barron, ${ }^{3}$ Laura Healy, ${ }^{4}$ Lorraine O'Connor, ${ }^{5}$ \\ Cara Synnott, ${ }^{1}$ Clíona Ní Cheallaigh, ${ }^{6,7}$ Colin P Doherty ${ }^{1,8,9}$
}

To cite: Doran E, Barron E, Healy L, et al. Improving access to epilepsy care for homeless patients in the Dublin Inner City: a collaborative quality improvement project joining hospital and community care. BMJ Open Quality 2021;10:e001367. doi:10.1136/ bmjoq-2021-001367

- Additional supplemental material is published online only. To view, please visit the journal online (http://dx.doi.org/10. 1136/bmjoq-2021-001367).

Received 2 February 2021 Revised 4 April 2021 Accepted 17 April 2021
Check for updates

(C) Author(s) (or their employer(s)) 2021. Re-use permitted under CC BY-NC. No commercial re-use. See rights and permissions. Published by BMJ.

For numbered affiliations see end of article.

Correspondence to Dr Elisabeth Doran; doranelisabeth@gmail.com

\section{ABSTRACT}

Homelessness is associated with significant psychosocial and health disparities. The rate of epilepsy among this cohort is eight times greater than that in the settled population, and the associated morbidity is higher due to lack of integrated care, difficulties with treatment adherence, substance abuse and poor social circumstances. There is a high rate of seizure-related death in homeless patients. Seizures are one of the most common neurological cause for emergency department presentation among this population. The aim of this quality improvement project was to use a multistakeholder coproduction approach to design a new pathway of care for homeless patients with epilepsy to improve access to specialist epilepsy care and to strengthen the links between hospital and community teams who manage this population. After several years of observation, stakeholder engagement and numerous tests of change, we have created a new care pathway and developed bespoke tools for primary care providers and for physicians working in the emergency department to enable them to assess and manage patients as they present, as well as provide access to remote epilepsy specialist support.

\section{INTRODUCTION}

Homelessness is associated with an increased mortality and high prevalence of chronic illnesses and substance use. ${ }^{12}$ The prevalence of epilepsy is estimated to be eight times higher than in the housed population, ${ }^{2}$ and seizure frequency increases when patients with epilepsy become homeless. ${ }^{3}$ Seizures are one of the most common neurological presentation to emergency departments in the homeless population. ${ }^{4}$ Seizures are less well controlled in homeless patients than housed patients with epilepsy for multiple reasons, including poor access to care, non-adherence, competing priorities and substance abuse. Poorly controlled seizures carry a substantial risk of injury and death. ${ }^{5}$ These factors have led to a lot of therapeutic nihilism on the part of care providers in the treatment of hospitalised homeless patients with seizures. The remarkably poor outcomes of epilepsy care in homeless people in Ireland is highlighted in work that has shown that in most epilepsyassociated deaths on the National Drugs and Alcohol-Related Death Index, there was little evidence at the time of death of antiepileptic drugs in the serum of those who died. ${ }^{6}$

Our epilepsy service is based in one of the Inner City Dublin Hospitals in Ireland and provides care to approximately 3000 patients with epilepsy within a defined geographical area. This includes a large part of the Dublin Inner City population, which has a high prevalence of homelessness, estimated $0.4 \%$ of the population in 2017. ${ }^{7}$ Currently, there are 4.550 adults officially in homeless emergency accommodation and at least 92 people sleeping rough in Dublin's city centre. ${ }^{8}$

Historically, homeless patients referred to our service with seizures were difficult to engage in care. They often present to the emergency department and leave before assessment is complete. Prior to our quality improvement project, all patients (housed and homeless) who presented with seizures were managed in our emergency department through our Integrated Care Pathway (ICP), which was developed in 2012 and has been shown to reduce hospital admissions for seizures. ${ }^{9}$ This pathway replaced the previous approach of admitting all patients with seizures. In the ICP, patients who fulfil certain criteria are discharged and reviewed by an epilepsy specialist in an outpatient setting within 1 month of presentation. However, it is difficult to provide care to homeless patients through this pathway because of difficulties in contacting them to arrange an outpatient review. Even when we managed to 
contact the patient or their keyworker, they regularly did not attend (DNA) the scheduled appointment. A 2016 internal audit of homeless patients' clinic attendance in our service showed that homeless patients had very high DNA rates of around $80 \%$. Instead of being seen in the outpatient setting to manage their epilepsy, these patients generally re-presented to the emergency department for acute treatment in the setting of seizures. Our experience of homeless and other vulnerable patients referred by community services has been very similar. ${ }^{10}$

Initially, we have planned to develop a community outreach service for homeless patients. This is a model of care that we have already developed successfully for patents with intellectual disability in residential care and has been described as a successful model in providing neurology care in the community for uninsured patients in the USA. ${ }^{11}$ This has been proven to be more difficult than expected because the homeless services in Dublin, like many capital cities, are fragmented and spread across numerous sites in the city. Furthermore, the patients are often mobile, drifting across health service jurisdictions, and their life circumstances change too quickly to be able to attend regular specialist clinics, even if provided on a community basis.

In 2017, our service employed a nurse specialist with dedicated hours for the creation of a homeless epilepsy service. At the time, we were still trialling outreach clinics and started virtual consultations with the community services, but there were no established protocols for the care of homeless patients with epilepsy and no defined pathways on how to engage with the community services. Due to the lack of structure, our efforts to engage with the patients and the community-based services often proved futile and unsatisfactory for all parties involved.

It was clear that we were failing to provide care for one of our most vulnerable patient groups. We needed to develop an approach that was more tailored to their needs.

In 2018, we started to engage with the community services in a more structured way using quality improvement methodology and a multistakeholder co-production design to develop a care pathway for homeless patients with seizures, by integrating care between the specialist service, the hospital and the homeless services in the community.

\section{METHODS}

Over the past 4 years, we have been dedicated to improving access to epilepsy care for homeless patients in our service. Figure 1 shows the timeline of audits, stakeholder engagements, interventions and process measures from 2016 to 2020.

Our standard yearly audit of our service provision in 2016 showed that regular scheduled outpatient appointments were not feasible for homeless patients with DNA rates of $80 \%$ in this group. To improve services, an initial trial of scheduled community outreach clinics and dedicated nurse-led virtual clinics showed that this intervention was not efficient due to the diversity of the needs of the patients and the low level of engagement with our service.

We decided to use a formal quality improvement methodology using multiple Plan-Do-Study-Act (PDSA) tests of change, in a multistakeholder, coproduction design which included team members from the epilepsy service, the inclusion health service of our hospital and primary care providers for homeless patients. At this time, we did not yet include homeless patients with epilepsy. From July 2018, we started systematically collecting data on all homeless patients referred to our service, including type of referral, diagnosis and ability to engage with the patient. These data were used as the baseline data for this quality improvement project.

\section{Step 1}

Established a stakeholder working group which included community service providers, hospital-based inclusion health team and epilepsy specialists and discussed strategies which could potentially help to improve care for homeless patients. Over four meetings, we exchanged ideas and process mapped the care process, developing a standard pro forma (online supplemental file 1) with an intelligent design, simple enough to be used during a general practitioner (GP) consultation. We initially trialled this Proforma with a small number of GPs and patients (PDSA1) and over several trials refined the tool.

\section{Step 2}

The tool was rolled it out to all the community GPs and implemented using another set of tests of change (PDSA2). The pro forma was used regularly by the community services, and we collected data communicating the information received through the proforma across the health system. The outcome and plan were created based on the pro forma information and is uploaded to the electronic patient record in the hospital, the national epilepsy patient record and fed back to the community, where it was uploaded to the community electronic patient record. We started collecting process measures on 46 patients as part of this PDSA using the optimised tool and compared them to a similar sized cohort from our baseline group with whom we had interacted with before the tool was launched.

\section{Step 3}

Up to this point, hospitalised homeless patients presenting with seizures in our hospital were typically admitted by general medical services and seen by the general neurology consultation service. The epilepsy service agreed to review all consults of homeless hospitalised patients presenting with seizures, even when they were not known to our service and had no diagnosis of epilepsy. We agreed to send copies of our assessments and management plans to the community services looking after the patient instead of hoping that our assessments 


\section{Process:}

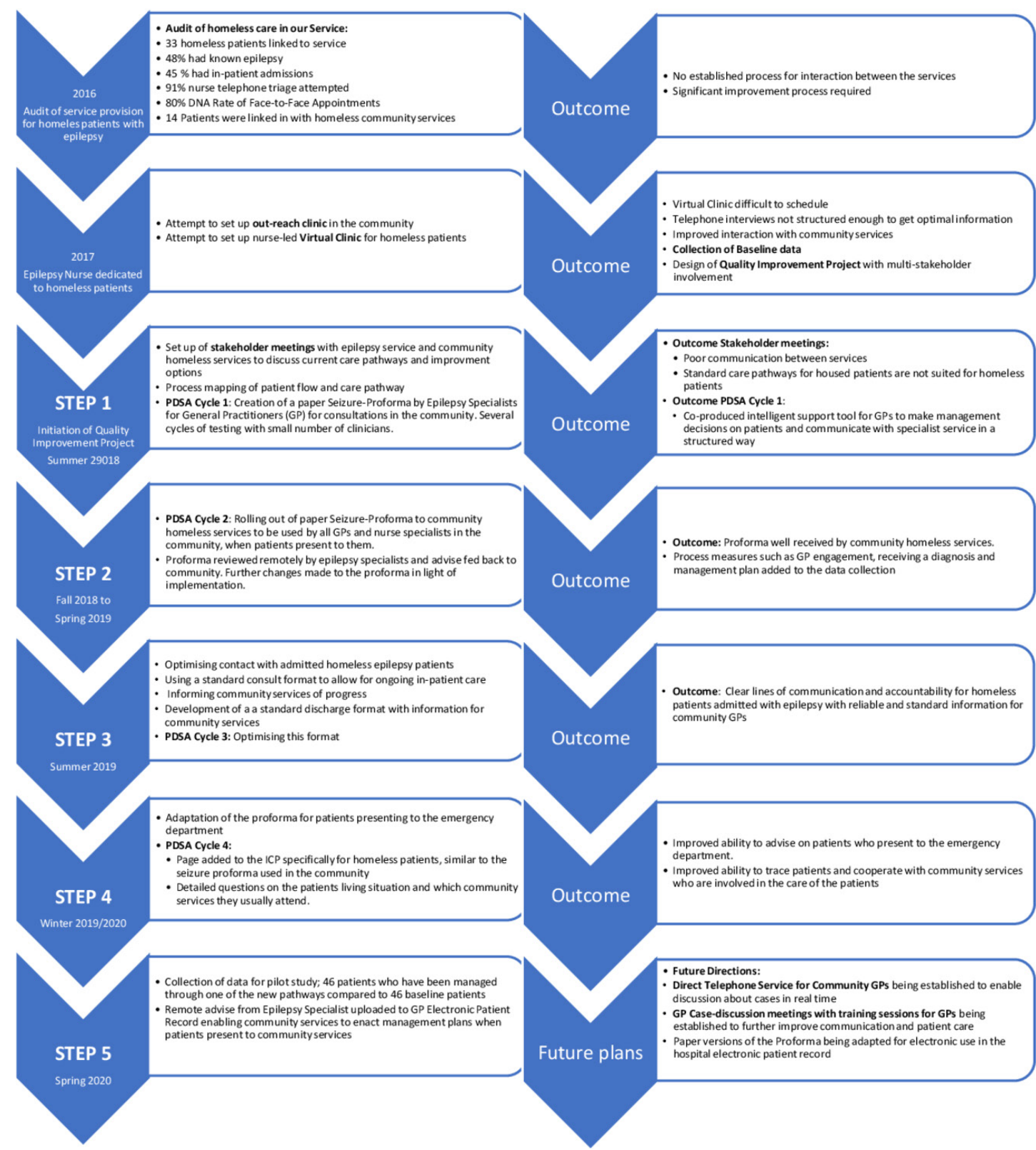

\section{Outcomes:}

Figure 1 Timeline of processes and outcomes of our quality improvement project between 2016 to 2020. ICP, Integrated Care Pathway; PDSA, Plan-Do-Study-Act.

would be copied into the general discharge letter. Using the seizure pro forma to review homeless inpatients with seizures and communicating the outcomes to the community services we set up another PDSA cycle (PDSA 3) to try and optimise contact with community services for hospitalised patients.

\section{Step 4}

Once we had established the seizure pro forma and pathway in the community, we adapted it and integrated it into the existing ICP for the emergency department (PDSA 4). When the Proforma is completed by ED physicians as part of the ED presentation and we receive the information from the emergency department, a management plan for the patient is made and the information uploaded to the hospital electronic record and forwarded to the community service providers instead of booking patients into the usual first seizure clinic. Please see figure 3 figure 2 for the pathway.

\section{Step 5}

As the pathways were operationalised, we audited several process measures on a pilot cohort of patients. We retrospectively reviewed referral information and attempted interventions for 46 homeless patients who were referred to us between July 2019 and February 2020. The data from the cohort were compared with data from a similar 
group of patents referred through our regular pathways before implementation of the new process.

We collected the patients' age and gender, epilepsy diagnosis, type of referral, ability to contact a patient or communicate a management plan to the primary care services and for the new cohort we also reviewed, whether or not we advised changes to the patient's seizure management based on the information we received.

Statistical analysis was performed using the Statistical Package for the Social Sciences V.230.0 for Windows. Any differences between cohorts were assessed using Pearson $\chi^{2}$ for categorical variables. For table 1, Fisher's exact test was used. Mann-Whitney $\mathrm{U}$ test and independent t-tests were used for continuous variables. The Standards for
Quality Improvement Reporting Excellence guidelines were used to write this quality improvement report. ${ }^{12}$

The audit was reviewed and authorised by the audit committee of St James's Hospital.

\section{RESULTS}

\section{New pathways of care}

The development of these new pathways was the result of several years of deliberative quality improvement work using multiple tests of change (four PDSA cycles) in a multistakeholder coproduction process. The result is captured in the annotated timeline in figure 1, and the final set of pathways is shown in figure 2 . Three bespoke

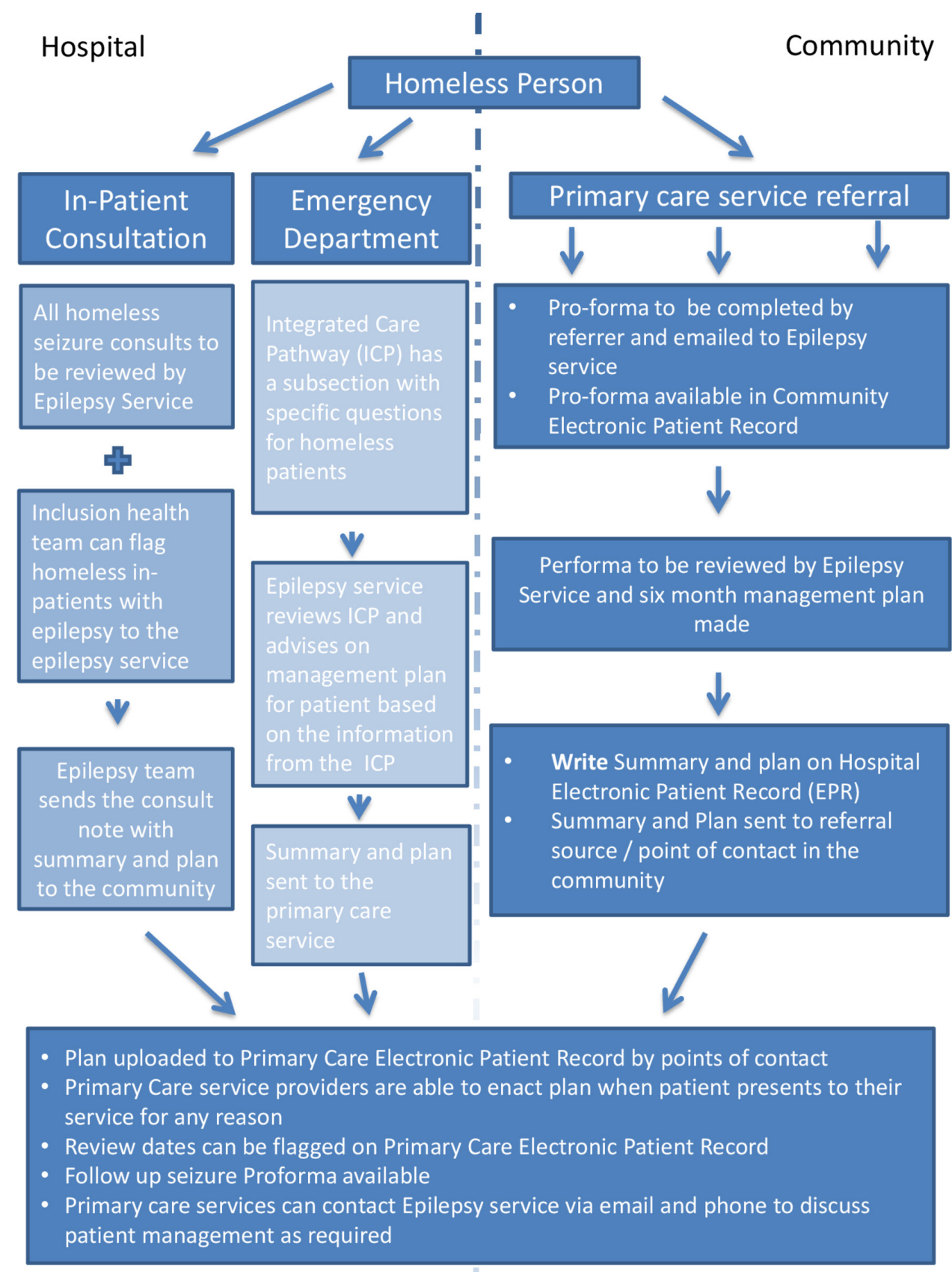

Figure 2 Newly established Clinical Pathways for homeless patients who are referred to our service. 
Table 1 Characteristics, process measures and comparison of two cohorts before and after the development of new pathways

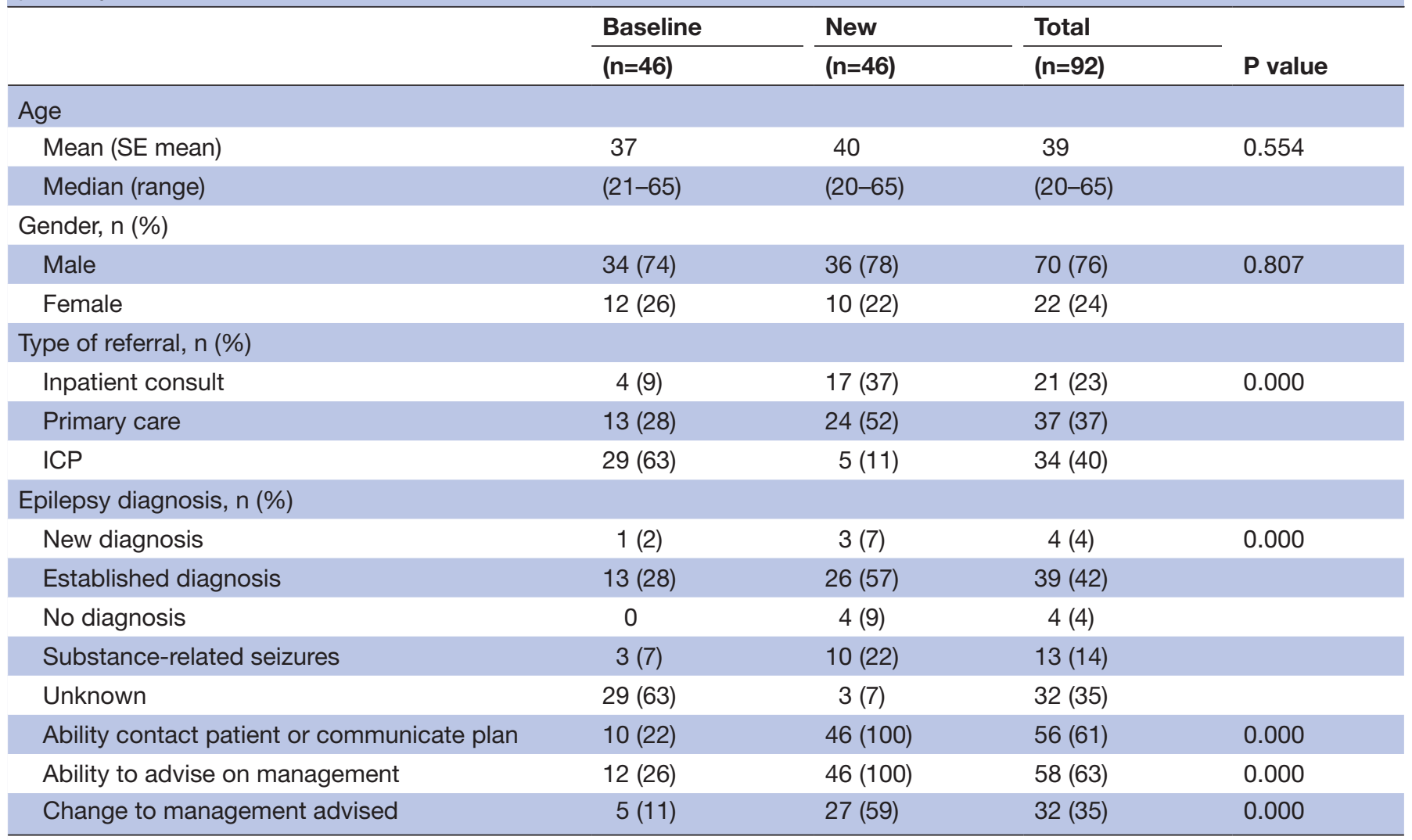

ICP, Integrated Care Pathway.

pathways were the overall result of these deliberations, plans, discussions and small tests of change. The first pathway allowed for direct and rapid specialist opinion for homeless patients with seizures in the community; the second pathway augmented the first pathway for hospitalised patients to allow direct communication of the discharge plan across the health system to GPs who form a network of primary care physicians who provide free primary care to homeless patients. Finally, we added a third pathway for the ED physicians to allow for communication with the specialist team and the community services.

\section{Pilot study process measures results}

Each cohort included 46 patients. The characteristics and process measures and results are summarised in table 1. The baseline cohort included 34 men and 12 women whose ages ranged between 21 and 65 years, with a median of 37 (mean 39). In $64 \%$ of the patients, the epilepsy diagnosis was not known; $28 \%$ of the patients had an established diagnosis of epilepsy. Patients had an average of 6.1 emergency room admission in the 12 months prior to this audit. Sixty-three per cent of the patients were referred through the ICP. Only 10\% of the patients referred through the ICP were contactable for follow-up. Overall, $13 \%$ of the referred patients were contactable.

The two cohorts were comparable in terms of age and gender. There were more referrals from the emergency department in the baseline cohort. In the new cohort, referrals were mostly from the primary care services; the reason for this imbalance is that we initially only changed the referral pathway for community referrals and only once this was established, we extended the strategy to the emergency department. There were also more patients in the new cohort that were referred to our service as inpatients because it was part of our strategy to see all homeless hospitalised patients presenting with seizures directly.

With our old process, referred patients were triaged via telephone first, and if we were able to contact them, they were booked to be reviewed in our clinic rather than extracting the relevant information at the time of contact and advising on management. The patient then often did not attend the clinic appointment, so we were not able to make a management plan for patients even when we were able to contact them initially. In the new cohort, using our newly implemented referral strategies, we were able to communicate a management plan to the primary care providers for all patients $(p$ value $=0.000$ )

Through our new strategy, we were able to find out enough information on the patient's history to be able to establish a diagnosis in $74 \%$ of patients compared with $38 \%$ of patients in the baseline cohort ( $\mathrm{p}$ value $=0.000$ ). In $59 \%$ of the patients, we did advise a change to their seizure management, which showed that most of the 
patients were suboptimally managed and benefitted from expert input.

It is too early to measure the outcomes such as improved seizure control and reduced presentation to the emergency department for these patients, but we are planning to evaluate these outcomes in the coming years.

Patients and the public were not directly involved in the quality improvement project because the reason for its initiation was that we failed to reach out to our homeless patients. In our standard care pathways, they missed appointments most of the time and we were not able to make contact with them. This was the reason for initiating this project and for engaging with the charity run community GPs who have a direct relationship with the homeless people in Dublin. Through the project, we were able to strengthen the relationship with the community and are able to support the community services who are directly involved. We are planning to directly involve homeless patients with epilepsy in the Dublin Inner service in future projects because through this quality improvement project we have found ways to engage with them directly.

\section{DISCUSSION}

In his book 52 Ways to Help Homeless People,${ }^{13}$ Grey Temple introduces his solutions with the following observation: 'Not all of these solutions are easy. Some of them are time consuming. Others require enlisting the efforts of other people who may or may not pay attention on the first pass. Many of them will result in emotional upheaval, mostly yours. Nevertheless, they are within your grasp. People like you have done every one of them. You don't need to be smart, rich, religious, expert, or especially brave. Yet, they will matter to people'. This paragraph has been highly motivating for our project. The formal structure of a quality improvement project often appeared chaotic and freewheeling at times. However, we believe that the story of this process is compelling, and the preliminary result has been an elegant set of bespoke pathways that have great potential to alter the care of this vulnerable group of patients for the better.

The prevalence of chronic health problems is high among homeless people. ${ }^{14}$ Epilepsy is a common chronic condition, more common than in housed people. ${ }^{3}$ Seizures frequently lead to ED admissions in homeless patients, ${ }^{4}$ and poorly controlled seizures increase mortality and morbidity in these patients. ${ }^{5}$ Homeless patients face many barriers in accessing appropriate healthcare. ${ }^{15}$ The whole process induces feelings of helplessness in specialist teams who are charged with providing diagnostic and therapeutic advice.

Different strategies have been proposed to improve access to healthcare for homeless patients. Supportive housing and case management strategies have been shown to be beneficial. ${ }^{16}$ Understandably, strategies to improve access to care are focused on access to primary care. ${ }^{17} 18$ However, as a specialist service, we had no direct access to these interventions which are focused on improving social circumstances and are typically facilitated by the community homeless services. We needed to find a way to support the primary care community-based homeless services with our specialist knowledge to enable them to manage patients' seizures.

Four years ago, we set out to try to improve access to specialist epilepsy care for homeless patients with seizures and this process is ongoing. In this article, we are providing an interim report on the process of developing new care pathways using a multistakeholder coproduction quality improvement design. We also report some preliminary process measures highlighting the barriers and facilitators of the current design.

We have described in detail the process of developing and implementing a set of pathways to enable primary care physicians to assess patients' seizures and allow us to remotely advise on patient care. The new pathways were established through multiple PDSA cycles which were built on to another to improve the processes. The formal reporting structures to capture the individual PDSA cycles would have exceeded the scope of this report, but the method was vital to structuring and evaluating the changes that were made to the service provision.

The pathways allow for dissemination of clinical information across different health jurisdictions to account for the often fragmented care these patients receive. Finally, we have integrated information gathering on this group of patients into our ICP in the emergency room so that this forms the basis of early referral to our services and those of inclusion health.

Our new strategy to engage with homeless patients has improved our ability to advise on epilepsy care significantly. The initiative has been very positively received by our primary care colleagues. Our project has helped to improve communication between our specialist service and the community services, and we have been able to develop a more reliable follow-up pathway for patients that we were unable to engage with beforehand. The strategy helps to improve communication between services and helps to integrate care.

\section{LIMITATIONS}

The strategy has only been implemented fully over the past year, so it is too early to establish whether outcome measures such as seizure control, emergency room visits or medication compliance can be improved with these pathways. We are prospectively following such outcomes and will report in due course.

The data that we collected did not lend itself to display as run charts, which makes it more difficult to interpret if the significant changes we found in our pilot data are truly a sign of an improvement in service delivery quality. The new changes we made were so simple that they are reflected as binary data-'able to make a diagnosis' (yes/no) and 'advise on treatment' (yes/no). However, making a positive diagnosis of epilepsy in patients who we 
were not able to interact with at all is a first step towards treating their epilepsy and reducing their risk of seizures.

We are currently recording further data, such as the new referrals and follow-up reviews of known patients per month, the number of emergency room presentations per month as well as inpatient admissions for seizures to continue to monitor if our processes are improving the care quality and are planning to report on this in due course.

One important weakness of the design process of the current pathways has been the lack of patients from the homeless group as part of the codesign process. There have been a number of informal discussions with patients, but they were not part of the initial coproduction process. It is our intention to refine the pathways with focus groups from this population. There are obvious difficulties recruiting such patients even in normal times but especially since the lockdowns and face-to-face restrictions that have been in place since the global COVID-19 pandemic.

\section{CONCLUSION}

This article describes the journey undertaken by a group of healthcare professionals in the quest to improve care for a vulnerable population of citizens. The development of the pathway was conceived and conducted as a coproduced quality improvement project over 4 years and has resulted in an elegant process for interacting with, delivering specialist advice on and improving care for homeless patients with epilepsy. Initial process measures are encouraging, and there is widespread support across the stakeholders for the pathways. Engagement with the patient group for pathway refinement will be important as will prospective measurement of outcome variables, and these will form the basis of a further report.

One thing that we have learnt is that for a specialist service that wants to improve access to care for homeless patients, making yourself remotely accessible to the primary care providing services and improving and standardising interservice communication structures are an efficient way to improve the quality of specialist care homeless patients receive.

We believe this work is generalisable to other services managing chronic diseases in homeless patients. Our pro forma is currently being adapted by other chronic disease management services in our hospital. We believe the pro forma can easily be adapted by other hospitals, in other countries and for other conditions.

\footnotetext{
Author affiliations

${ }^{1}$ Neurology, Saint James's Hospital, Dublin, Ireland

${ }^{2}$ Neurologie, Sankt Georg Hospital Group, Leipzig, Germany

${ }^{3}$ Primay Care, Safety Net Primary Care, Dublin, Ireland

${ }^{4}$ Clinical Nutrition, Saint James's Hospital, Dublin, Ireland

${ }^{5}$ Epilepsy Action Australia, Sydney, New South Wales, Australia

${ }^{6}$ Inclusion Health, Saint James's Hospital, Dublin, Ireland

${ }^{7}$ Clinical Medicine, Trinity College Dublin, Dublin, Ireland

${ }^{8}$ Neurology, TCD, Dublin, Ireland
}

${ }^{9}$ FutureNeuro SFI research center for rare and chronic neurological diseases, Royal College of Surgeon's in Ireland, Dublin, Ireland

Correction notice This article has been corrected since it was first published. The name of the author 'Colin P Doherty' and their affiliations have been corrected.

Acknowledgements Slainte Care has helped to fund this project (project number 366).

Contributors ED and EB developed the Proforma. LOC, ED and CS collected the Data. CD led the project. LH performed the statistical analysis. ED and CD wrote the article. CNC edited and reviewed the article. All authors contributed to the pathways that were developed and reviewed the article.

Competing interests None declared.

Patient consent for publication Not required.

Provenance and peer review Not commissioned; externally peer reviewed.

Supplemental material This content has been supplied by the author(s). It has not been vetted by BMJ Publishing Group Limited (BMJ) and may not have been peer-reviewed. Any opinions or recommendations discussed are solely those of the author(s) and are not endorsed by BMJ. BMJ disclaims all liability and responsibility arising from any reliance placed on the content. Where the content includes any translated material, BMJ does not warrant the accuracy and reliability of the translations (including but not limited to local regulations, clinical guidelines, terminology, drug names and drug dosages), and is not responsible for any error and/or omissions arising from translation and adaptation or otherwise.

Open access This is an open access article distributed in accordance with the Creative Commons Attribution Non Commercial (CC BY-NC 4.0) license, which permits others to distribute, remix, adapt, build upon this work non-commercially, and license their derivative works on different terms, provided the original work is properly cited, appropriate credit is given, any changes made indicated, and the use is non-commercial. See: http://creativecommons.org/licenses/by-nc/4.0/.

ORCID iD

Elisabeth Doran http://orcid.org/0000-0003-0770-285X

\section{REFERENCES}

1 Brett T, Arnold-Reed DE, Troeung L, et al. Multimorbidity in a marginalised, street-health Australian population: a retrospective cohort study. BMJ Open 2014;4:e005461.

2 O'Reilly F, Barror S, Hannigan A. Homelessness: an unhealthy state. health status, risk behaviours and service utilisation among homeless people in two Irish cities. Dublin: The Partnership for Health Equity, 2015.

3 Laporte A, Rouvel-Tallec A, Grosdidier E, et al. Epilepsy among the homeless: prevalence and characteristics. Eur J Public Health 2006;16:484-6.

4 Rosendale N, Guterman EL, Betjemann JP, et al. Hospital admission and readmission among homeless patients with neurologic disease. Neurology 2019;92:e2822-31.

5 Ficker DM. Sudden unexplained death and injury in epilepsy. Epilepsia 2000;41:S7-12.

6 Lynn E, Lyons S, Langan Y, et al. The role of alcohol dependency in deaths among people with epilepsy recorded by the National drug-related deaths index (NDRDI) in Ireland, 2004-2013. Seizure 2017;45:52-5.

7 Ní Cheallaigh C, Cullivan S, Sears J, et al. Usage of unscheduled hospital care by homeless individuals in Dublin, ireland: a crosssectional study. BMJ Open 2017;7:e016420.

8 Department of Housing, Local Government and Heritage. Homeless Report - February 2020. Available: https://www.housing.gov.ie/sites/ default/files/publications/files/homeless_report_-_february_2020.pdf [Accessed 04 Apr 2020].

9 Williams J, Doherty J, Di Blasi C, et al. Seizure care in the emergency department. identifying and bridging the gaps. A study of care and outcomes from 644 seizure presentations. Epilepsy Behav 2018;78:226-31.

10 Haque A, Doherty C, Williams J. Non-attendance of vulnerable populations within epilepsy outpatient services in Ireland. Ir J Med Sci 2018;187:525-8.

11 Taylor JJ, Larrew T, Omole A, et al. The feasibility of establishing a free clinic for uninsured patients with neurologic disorders. Neurol Clin Pract 2015;5:302-8.

12 Ogrinc G, Davies L, Goodman D, et al. Squire 2.0 (standards for quality improvement reporting excellence): revised publication 
guidelines from a detailed consensus process. Am J Crit Care 2015;24:466-73.

13 Temple G. 52 ways to help homeless people. Oliver-Nelson Pub 1991:11.

14 Nikoo N, Motamed M, Nikoo MA. Chronic physical health conditions among homeless. J Health Dispar Res Pract 2014;8:5.

15 Hwang SW. Homelessness and health. CMAJ 2001;164:229-33.

16 Hwang SW, Burns T. Health interventions for people who are homeless. Lancet 2014;384:1541-7.
17 White BM, Newman SD. Access to primary care services among the homeless: a synthesis of the literature using the equity of access to medical care framework. J Prim Care Community Health 2015;6:77-87.

18 Jego M, Abcaya J, Ștefan D-E, et al. Improving health care management in primary care for homeless people: a literature review. Int J Environ Res Public Health 2018;15:309. 